\title{
NÍVEL DE INSTRUÇÃO DE PRODUTORES RURAIS E AS CARACTERÍSTICAS DA PRODUÇÃO LEITEIRA
}

\author{
PICOLI, Tony ${ }^{1}$ \\ ZANI, João Luíz ${ }^{2}$ \\ PETER, Cristina Mendes ${ }^{3}$; \\ LATOSINSKI, Giulia Soares ${ }^{4}$; \\ FISCHER, Geferson ${ }^{2}$.
}

\begin{abstract}
${ }^{1}$ Doutorando do Programa de Pós-Graduação em Veterinária - UFPEL, ${ }^{2}$ Professor Adjunto do Departamento de Veterinária Preventiva - UFPEL, ${ }^{3}$ Mestranda do Programa de Pós-Graduação em Veterinária - UFPEL, ${ }^{4}$ Acadêmica da Faculdade de Veterinária - UFPEL.
\end{abstract}

\section{RESUMO}

$\mathrm{N}$ o Brasil, existem produtores de leite especializados com alta produção e um número considerável de pequenos produtores produzindo pequeno volume de leite com baixa qualidade. Sabe-se que o grau de instrução dos produtores pode determinar melhores índices produtivos na atividade leiteira. Neste estudo, objetivou-se relacionar distintas formas de produção leiteira com o grau de instrução dos produtores. Em 274 unidades de produção de leite (UPL) do Rio Grande do Sul, foram colhidas amostras de leite e foram aplicados questionários epidemiológicos aos produtores. Em média, as UPL apresentam 8,4 vacas em lactação e 4,4 vacas secas, produção de 78,9 L/dia, e produtividade de 9,3 L/vaca/dia. Há UPL que utilizam sua área apenas para pecuária leiteira (46\%) e as que utilizam também para lavoura (54\%). Houve maior Contagem Bacteriana Total (CBT) em UPL que trabalham com ambas atividades $(p<0,05)$, e a contagem de células somáticas (CCS) menor em UPL cujos produtores eram mais escolarizados. Esses produtores realizam com maior frequência o tratamento de vacas secas $(p<0,01)$ e a realização de inseminação artificial aumentou a produção da UPL $(p<0,05)$. Quanto à ordenha mecânica, há diferença na realização de manutenção do equipamento que é mais realizado por produtores mais instruídos $(p<0,01)$. O nível de instrução pode interferir na adesão de técnicas que cursem com qualidade do leite produzido.

Palavras-chave: Ordenha. Instrução. Produtor de leite. 


\section{INTRODUÇÃO}

O leite é uma emulsão de cor branca, odor suave e gosto adocicado, secretado das glândulas mamárias de vacas leiteiras (KRUG et al., 1993). Devido à sua importância alimentar, o leite deve exercer a função nutricional de forma segura, sem colocar em risco a saúde do consumidor.

A produção de leite no Brasil possui importância socioeconômica significativa, sendo o quinto maior produtor mundial, registrando uma produção de 31,2 milhões de toneladas (FAO, 2011). Dentre os estados brasileiros, o Rio Grande do Sul é o segundo produtor nacional de leite, com 10,6\% da produção brasileira (IBGE, 2013). Apesar da relevância da produção leiteira no país, existem fatores que comprometem seu progresso impedindo melhor desenvolvimento. $\mathrm{O}$ baixo nível de instrução dos produtores e a falta de assistência técnica em pequenas propriedades, por exemplo, são entraves no avanço da produção de leite com qualidade (SCALCO; SOUZA, 2006).

A produção leiteira no país aumenta ano após ano, assim como a competitividade entre os sistemas de produção e a cobrança por melhor qualidade do produto obtido. A Instrução Normativa 51 (IN51), implementada em 2002, contribuiu para melhoria da qualidade do leite no país. Em 2012, a IN51 foi substituída pela IN62, que determina limites para as contagem de células somáticas (CCS) e contagem bacteriana total (CBT), de 600 mil células/mL de leite e 600 mil Unidades Formadoras de Colônias (UFC)/mL de leite cru refrigerado, respectivamente (BRASIL, 2011). Esses novos padrões estão fazendo com que os produtores alterem a tradicional forma de obtenção do leite, a fim de se adequar a nova legislação vigente.

De forma geral, os produtores de leite no Brasil dividem-se entre dois grupos distintos: poucos produtores especializados, porém com alta produtividade, e grande quantidade de pequenos produtores, pouco ou nada especializados, que produzem pequeno volume diário, de leite com baixa qualidade. O segundo grupo, no entanto, corresponde a uma grande parcela do leite produzido no país (MILINSKI et al., 2008).

A presença de contaminantes no leite pode comprometer sua qualidade, causando modificações que limitam a durabilidade do produto e de seus derivados (FREITAS et al., 
2002). A multiplicação microbiana pode acontecer antes ou após a ordenha, devido à falta de higienização do ambiente, equipamentos, homem e em decorrência de enfermidades, como a mastite, que compromete a glândula mamária (MACHADO et al., 1998).

Devido à necessidade de incremento nos padrões produtivos da atividade leiteira no Brasil, torna-se importante conhecer os fatores que influenciam a produção e os ganhos do produtor. Assim sendo, objetivou-se conhecer as distintas formas de produção de leite em municípios da região sul do Rio Grande do Sul, e correlacioná-las com o grau de instrução dos produtores.

\section{MATERIAL E MÉTODOS}

Este trabalho foi realizado na mesorregião do sudeste do Rio Grande do Sul, incluindo municípios da microrregião de Pelotas e o município de Rio Grande, pertencente à microrregião do Litoral Lagunar. Respeitando o número de UPL em cada município e o pulo amostral estabelecido, foram selecionadas aleatoriamente 274 UPL, onde foi aplicado um questionário epidemiológico que buscou, de forma simples e direta, identificar as características do sistema de produção. Foram aplicadas questões estruturadas e planejadas para atingir os objetivos da pesquisa, que abordou temas como a caracterização do proprietário, da propriedade e da produção, com ênfase para o processo de ordenha, equipamentos, higiene e manejo dos animais.

Além disso, foram coletadas duas amostras de leite diretamente do resfriador. Em casos de tanque de expansão, as pás giratórias do equipamento foram ligadas durante cinco minutos antes da coleta, para adequada homogeneização e, em caso de latão em tanque de imersão, o leite foi homogeneizado com um mexedor inoxidável de cabo longo, devidamente higienizado. As amostras foram acondicionadas em recipientes de polietileno estéreis contendo conservantes, um com bronopol e outro com azidiol. As amostras foram encaminhadas, sob refrigeração, ao Laboratório de Qualidade de Leite da Empresa Brasileira de pesquisa Agropecuária - EMBRAPA Clima Temperado, para realização da CCS e CBT, em equipamento automático com contagem eletrônica por citometria de fluxo. 
As variáveis qualitativas foram analisadas em função da frequência de respostas aos questionários, pelo teste Qui-quadrado, enquanto que as quantitativas, através do teste $T$ de Student, com nível de significância de 95\%, através do software BioEstat versão 5.3.

\section{RESULTADOS E DISCUSSÃO}

Através dos questionários pôde-se verificar que, na região sul do Rio Grande do Sul, a atividade leiteira é realizada em propriedades com tamanho médio de 26,1 ha e que muitas UPL utilizam sua área também para a agricultura. A área média utilizada para produção de leite foi de 16,02 ha e a área média utilizada para agricultura foi de 10,7 ha. Segundo Schneider (2003), a maioria das UPL da região sul do Rio Grande do Sul são de agricultura familiar, e encaram a produção de leite como um complemento das demais atividades da propriedade. Em média, as UPL apresentam 8,4 vacas em lactação e 4,4 vacas secas com produção média de 78,9 L/dia e uma produtividade média de 9,3 L/vaca/dia. Das 274 UPL visitadas, 126 (46\%) utilizam sua área apenas para pecuária leiteira e 148 (54\%) utilizam a área também para lavoura. Observa-se que, em UPL cuja atividade leiteira é atividade exclusiva, os índices produtivos são melhores que nas UPL que trabalham com as duas atividades. A Tabela 1 apresenta os índices produtivos relativos aos dois tipos de UPL.

Tabela 1 - Índices produtivos de acordo com a utilização da área da propriedade.

\begin{tabular}{lcc}
\hline & $\begin{array}{c}\text { Pecuária leiteira } \\
(\mathbf{n}=\mathbf{1 2 6})\end{array}$ & $\begin{array}{c}\text { Pecuária leiteira + } \\
\text { Lavoura ( } \mathbf{n = 1 4 8 )}\end{array}$ \\
\hline Vacas em lactação & $\mathrm{n}=10$ & $\mathrm{n}=7,1$ \\
Vacas secas & $\mathrm{n}=5,7$ & $\mathrm{n}=3,4$ \\
Produção diária & $102,6 \mathrm{~L} /$ dia & $58,6 \mathrm{~L} /$ dia** \\
Produtividade média & $10,2 \mathrm{~L} / \mathrm{vaca} /$ dia & $8,3 \mathrm{~L} / \mathrm{vaca} /$ dia \\
CCS (cél/mL) & $5,51 \times 10^{5}$ & $5,35 \times 10^{5}$ \\
CBT (UFC/mL) & $2,51 \times 10^{6}$ & $4,08 \times 10^{6 *}$ \\
\hline$*(p<0,05)^{* *}(p<0,001)-$ Diferença estatística significativa.
\end{tabular}

$*(p<0,05) ; * *(p<0,001)$ - Diferença estatística significativa. 
Houve diferença significativa quanto à produção média diária entre os grupos de produtores que realizam apenas a pecuária leiteira em sua propriedade e os produtores que praticam a agricultura conjuntamente $(p<0,001)$, comprovando que o grau de comprometimento com a produção leiteira pode afetar a quantidade produzida diariamente, bem como os ganhos com a entrega do leite à indústria. Esses ganhos também são afetados pela CBT (um dos parâmetros utilizados pela legislação para avaliar qualidade e instituir pagamento), que também apresentou diferença significativa entre os grupos.

A média geral da CBT foi de $3,41 \times 10^{6} \mathrm{UFC} / \mathrm{mL}$ de leite, e apenas $133(48,5 \%)$ UPL estavam de acordo com os padrões exigidos pela IN62. Esse dado demonstra que um dos grandes entraves na produção leiteira é a higiene, visto que os números se encontram bem acima do recomendado pela legislação. Nota-se que as UPL dedicadas exclusivamente à pecuária leiteira, além de apresentar melhores índices produtivos como produção e produtividade diárias, apresentam também uma melhor qualidade do leite, no que diz respeito à higiene do processo de obtenção e armazenamento. Segundo Behmer (1984), a principal fonte de contaminação do leite, excetuando a mastite, é o ambiente contaminado, principalmente com fezes dos animais. Essa contaminação ocorre pela ordenha realizada de forma incorreta, sem a devida higiene. Outra forma comum de contaminação do produto são os latões mal higienizados, utilizados para estocagem do leite. Com relação à CCS, a média geral foi de 5,42 x 10 células/mL de leite e 197 UPL (71,9\%) estavam de acordo com as exigências da legislação. O desafio dos pequenos produtores é conseguir se adequar e produzir leite dentro dos parâmetros mínimos de qualidade impostos pela legislação. A adequação demanda investimentos, e muitos pequenos produtores, sem condições financeiras e técnicas, acabam por abandonar a atividade leiteira.

Além da forma como a área da UPL é utilizada (apenas leite ou leite associado à agricultura), há outros fatores que podem contribuir para a forma como o leite é produzido, como o grau de instrução dos responsáveis. Para análise desses dados, os responsáveis pela UPL foram separados em três grupos. Grupo 1 (analfabetos e ensino fundamental incompleto), grupo 2 (ensino fundamental completo e ensino médio incompleto) e grupo 3 (ensino médio completo e ensino superior). Produtores do grupo 1 compreendem 27,7\% das UPL, grupo 2, 
66,8\% das UPL e grupo 3, apenas 5,5\% das UPL. Constatou-se que, em sua maioria, os produtores não tem instrução suficiente para produzir leite com qualidade aceitável e, têm dificuldades de entender a importância da adequação às legislações vigentes (SCALCO; SOUZA, 2006).

Quanto à CCS, os grupos 1, 2 e 3, respectivamente apresentaram as seguintes médias: 6,59 x $10^{6} ; 5,49 \times 10^{5}$ e $3,38 \times 10^{5}$ células $/ \mathrm{mL}$ de leite. Já quanto à CBT as médias foram, respectivamente $3,92 \times 10^{6} ; 2,6 \times 10^{6}$ e $2,3 \times 10^{6} \mathrm{UFC} / \mathrm{mL}$ de leite. Houve diferença estatística entre os grupos de escolaridade, em que o grupo menos escolarizado apresentou médias menos satisfatórias que os demais grupos $(p<0,05)$. Entre os grupos 2 e 3 , houve diferença somente quanto à CCS $(p<0,05)$, sendo que o grupo mais instruído apresentou contagem mais baixa. Os produtores com menor instrução apresentaram piores resultados frente aos demais grupos, sugerindo que o nível de instrução tem influência sobre os parâmetros da qualidade do leite (CCS e CBT).

Quanto à utilização da área da UPL, realizam apenas a atividade leiteira $37,3 \%$ dos produtores que compreendem o grupo $1,48,9 \%$ do grupo 2 e 53,3\% do grupo 3 . Integram a agricultura conjuntamente $62,7 \%$ do grupo $1,51,1 \%$ do grupo 2 e $46,7 \%$ do grupo 3 . Os dados permitem observar que quanto maior o grau de instrução do produtor, maior sua especialização na atividade leiteira $(p=0,028)$. A tabela 2 apresenta a frequência com que algumas técnicas de manejo são praticadas, de acordo com o grau de instrução dos produtores. 
Tabela 2 - Frequência de adesão a técnicas de manejo em função do grau de instrução dos produtores e índices produtivos alcançados.

\begin{tabular}{|c|c|c|c|c|c|c|}
\hline & & \multicolumn{3}{|c|}{ Grau de Instrução } & \multicolumn{2}{|c|}{ Índices Produtivos } \\
\hline & & $\begin{array}{c}\text { Grupo } 1 \\
\text { (\%) }\end{array}$ & $\begin{array}{c}\text { Grupo } 2 \\
\text { (\%) }\end{array}$ & $\begin{array}{c}\text { Grupo } 3 \\
\text { (\%) }\end{array}$ & $\begin{array}{l}\text { Produção } \\
\text { (L/dia) }\end{array}$ & $\begin{array}{l}\text { Produtividade } \\
\text { (L/dia/vaca) }\end{array}$ \\
\hline Manejo & Monta Natural & 62,7 & 59 & 60 & $68,9 a$ & 9,8 \\
\hline reprodutivo & Inseminação & 37,3 & 41 & 40 & $137,7 b^{*}$ & 13 \\
\hline \multirow[t]{2}{*}{ Ordenha } & Manual & 37,3 & 42,6 & 13,3 & 51,3 & 9,7 \\
\hline & Mecânica & 62,7 & 57,4 & 86,7 & 133,9 & 12,8 \\
\hline Lavagem do & Com água & 94,7 & 95,1 & 80 & 100,2 & 11,9 \\
\hline Teto & Não Lavam & 5,3 & 4,9 & 20 & 125,3 & 12,6 \\
\hline \multirow[t]{2}{*}{ Pré-dipping } & Realizam & 10,7 & 14,8 & 26,7 & 197 & 13,7 \\
\hline & Não Realizam & 89,3 & 85,2 & 73,3 & 84,2 & 12,2 \\
\hline \multirow[t]{2}{*}{ Pós-dipping } & Realizam & 25,3 & 21,9 & 46,7 & 171,5 & 13,5 \\
\hline & Não Realizam & 74,7 & 78,1 & 53,3 & 78,7 & 12,1 \\
\hline $\begin{array}{l}\text { Ambas } \\
\text { desinfecções }\end{array}$ & Realizam & 10,7 & 11,5 & 26,7 & 211,4 & 12,9 \\
\hline Diagnóstico & Realizam & 17,3 & 10,9 & 26,7 & 130,4 & 14,1 \\
\hline para mastite & Não Realizam & 82,7 & 89,1 & 73,3 & 96,5 & 12,2 \\
\hline $\begin{array}{l}\text { Tratamento } \\
\text { de Vacas }\end{array}$ & Realizam & $52 a$ & $35,5 a$ & $60 \mathrm{~b} * *$ & 126,2 & 12,5 \\
\hline Secas & Não Realizam & 48 & 64,5 & 40 & 83,5 & 12,5 \\
\hline
\end{tabular}

Grupo 1 - Produtores analfabetos e com ensino fundamental incompleto.

Grupo 2 - Produtores com ensino fundamental completo e ensino médio incompleto.

Grupo 3-Produtores com ensino médio completo e ensino superior iniciado.

Letras diferentes representam diferença estatística.

$*(p<0,05)$ Teste $T$ de Student.

**( $p<0,01)$ Teste Qui-Quadrado. 
Quanto ao manejo reprodutivo, $165(60,2 \%)$ UPL realizam a monta natural e obtém produção média de 68,9 L/dia e uma produtividade média de 9,8 L/vaca/dia. A inseminação artificial é realizada por 109 (39,8\%) das UPL, que obtém produção média de 137,7 L/dia e produtividade média de $13 \mathrm{~L} / \mathrm{vaca} /$ dia. Embora pareça existir uma tendência a aumentar a adesão à inseminação artificial conforme se aumenta o grau de instrução, neste estudo não houve diferença estatística entre os resultados obtidos. No entanto, houve diferença significativa $(p<0,05)$ no que diz respeito à produção leiteira diária das UPL que inseminam quando comparado às UPL que utilizam monta natural.

Atualmente, a maioria dos produtores do estudo realizam a ordenha dos animais de forma mecanizada (60,7\%), atingindo uma produção média diária de 133,9 L/dia com produtividade média de 12,8 L/vaca/dia. Já os produtores que ainda realizam a ordenha de forma manual (39,3\%) atingem média de produção diária de apenas 51,3 L/dia com produtividade média de 9,7 L/vaca/dia. Embora sem comprovação estatística, nota-se uma aparente diferença nas porcentagens de adesão aos tipos de ordenha segundo o grau de instrução, sendo que $37,3 \%$ dos produtores do grupo 1 ainda ordenham seus animais manualmente ao passo que apenas $13,3 \%$ dos produtores do grupo 3 realizam a técnica dessa forma. A ordenha mecanizada é realizada por $62,7 \%$ dos produtores menos instruídos e por $86,7 \%$ dos produtores mais instruídos. Há algum tempo, o produtor ficava receoso em adquirir um equipamento mecanizado para ordenha, em função dos altos custos de implementação. Hoje, no entanto, além do apelo comercial, a ordenha mecânica é cada vez mais necessária para facilitar o manejo com os animais. Além disso, quanto à forma de aproveitamento do espaço na propriedade, houve diferença significativa quanto à técnica adotada para a ordenha $(p<0,01)$, onde $63 \%$ das UPL que integram a lavoura com a atividade leiteira realizam ordenha manual e as UPL com dedicação exclusiva à pecuária leiteira ordenham seus animais manualmente em apenas $37 \%$ dos casos. As UPL que se dedicam exclusivamente à pecuária leiteira têm maior adesão à ordenha mecanizada, ao passo que as UPL que integram agricultura têm menor taxa de adesão à técnica. Isso ocorre pelo grau de comprometimento com a atividade leiteira, já que no primeiro caso, o leite é a principal fonte de renda da propriedade. A Tabela 3 aponta o manejo com o equipamento de ordenha. 
O grupo com menor instrução é o que menos realiza a manutenção do equipamento, diferindo estatisticamente $(p<0,01)$ dos dois grupos de maior instrução. É recomendada a manutenção do nível de vácuo, do número de pulsações e a troca periódica das borrachas e mangueiras (CBQL, 2004). Não houve diferenças estatísticas entre os grupos de produtores que utilizam ou não os produtos indicados para higienização do equipamento de ordenha. Porém, nota-se maior adesão ao uso do detergente ácido $(50,6 \%)$, ao passo que o detergente alcalino é utilizado em apenas $28,9 \%$ dos casos.

Tabela 3 - Cuidados com equipamento de ordenha mecanizada, segundo o grau de instrução dos produtores.

\begin{tabular}{lcccc}
\hline & & \multicolumn{3}{c}{ Grau de instrução } \\
\cline { 3 - 5 } & produtores & Grupo 1 (\%) & Grupo 2 (\%) & Grupo 3 (\%) \\
\hline Manutenção no último ano & 80,7 & $61,7^{\mathrm{a}}$ & $89,5^{\mathrm{b}}$ & $84,6^{\mathrm{b}}$ \\
Uso detergente ácido & 50,6 & 55,3 & 50,5 & 38,5 \\
Uso detergente alcalino & 28,9 & 27,7 & 28,6 & 38,5 \\
\hline
\end{tabular}

Letras diferentes na mesma linha significam diferença estatística $(p<0,01)$.

A desinfecção dos tetos pré-ordenha (pré-dipping) é realizada por apenas $14,2 \%$ dos produtores. É uma baixa porcentagem de adesão, visto a importância da técnica que visa impedir a disseminação de patógenos no rebanho. Não houve diferença estatística no presente estudo, porém nota-se maior frequência de utilização da técnica no grupo de produtores com maior grau de escolaridade e a maior produção (197 L/dia) e produtividade média (12,2 L/vaca/dia) no grupo de produtores que realizam a técnica, o que demonstra a importância da instrução na atividade leiteira. Na desinfecção dos tetos pós-ordenha (pósdipping) observou-se o mesmo comportamento, com produtores com maior grau de instrução tendendo a realizar a técnica e os índices produtivos melhores (produção: 171,5 L/dia e produtividade: 13,5 L/vaca/dia). O seleto grupo de produtores que realizam tanto o pré quanto o pós-dipping (12\%), apresenta produção média de 211,4 L/dia, com produtividade média de 12,9 L/vaca/dia. Esses bons resultados na produção leiteira são atingidos devido ao sinergismo do pré e pós-dipping que são realizados por $26,7 \%$ dos 
produtores do grupo 3 e por apenas 10,7\% do grupo 1 e 11,5\% do grupo 2. Portanto, nota-se uma influência do grau de instrução agindo positivamente sobre a adesão das duas técnicas concomitantemente. Esses dados ressaltam a importância das desinfecções dos tetos antes e após e ordenha, diminuindo os riscos de contaminação por microrganismos infecciosos e ambientais, baixando os índices de mastite na propriedade leiteira, melhorando assim parâmetros utilizados para a avaliação da qualidade do leite como a CCS e CBT que também se encontram com resultados mais satisfatórios em UPL cujos responsáveis são mais instruídos. Quanto aos diagnósticos para mastite, apenas 13,5\% dos produtores afirmam realizar algum tipo de técnica e, destes, 12,4\% realizam teste da caneca de fundo escuro, 46,6\% o California Mastitis Test (CMT), com frequências muito variadas, existindo aqueles que afirmam realizar todos os dias até os que dizem realizar apenas quando há suspeita de mastite. Os outros $41 \%$ de produtores que fazem testes, consideram o teste do álcool, realizado pelo responsável pela coleta do leite na propriedade, como teste diagnóstico para mastite. Este teste visa demonstrar a estabilidade das proteínas do leite frente ao álcool e é um indicativo que as proteínas não precipitariam frente ao tratamento térmico (GUO et al., 1998). Nota-se uma maior tendência à realização de testes diagnósticos em produtores com nível de escolaridade maior.

Quanto à administração de antibióticos na atividade leiteira, Rebuhn (2000) afirma que o tratamento na secagem das vacas corresponde a um ponto importante no controle da mastite, pois garante que a próxima lactação inicie com a glândula mamária saudável. Nesse sentido, 41,2\% dos entrevistados afirmam realizar o tratamento das vacas secas e, destes, $23 \%$ realizam rodízio de antibióticos ao término de diferentes lactações. A produção do grupo que não realiza o tratamento foi de $83,5 \mathrm{~L} /$ dia contra 126,2 L/dia do grupo que faz o tratamento de vaca seca. Essa diferença pode estar ligada ao fato do tratamento de vacas secas ser mais realizado em propriedades maiores e mais especializadas na produção de leite. Houve diferença significativa quanto à realização do tratamento de vacas secas em relação à instrução dos produtores $(p<0,01)$, deixando claro, mais uma vez, a importância da instrução para que técnicas consideradas ideais sejam adotadas. 


\section{CONCLUSÃO}

Através da análise dos dados, sugere-se que os produtores de leite da mesorregião sudeste do estado do Rio Grande do Sul não têm instrução suficiente para compreender a importância de técnicas de manejo adequadas para produzir leite, cujos parâmetros estejam totalmente em conformidade com a legislação. A baixa escolaridade dos produtores também pode influir na condição econômica da zona rural da região que, em pequenas propriedades, comumente é baixa, dificultando o acesso a equipamentos e/ou produtos adequados para a atividade leiteira. As técnicas de manejo consideradas inadequadas são praticadas com maior frequência por produtores que têm menor grau de instrução. Os índices produtivos estão diretamente vinculados ao grau de conhecimento do produtor, constatando-se que quanto maior o nível de instrução, melhores são os índices produtivos (produção diária da UPL e produtividade dos animais).

\section{LEVEL OF EDUCATION OF FARMERS AND THE CHARACTERISTICS OF MILK PRODUCTION}

\section{ABSTRACT}

I n Brazil, milk production is basically characterized by highly technified dairy farms and also by a substantial number of small family farms with little or no specialized technology. The level of education of milk producers may determine an increase in the milk yield and a substantial improvement in its microbiological quality. The objective of this study was to know about the different ways of milk production and to establish a correlation with the education level of milk farmers. 274 units of milk production (UMP) of Rio Grande do Sul were studied. Bulk tank milk samples were collected from all the farms and an epidemiological questionnaire was applied to the producers. The average number of lactating cows in the UMP was 84 with a milk production of $78,9 \mathrm{~L} /$ day and the average milk yield per cow was 9,3L. Regarding the total area in each UMP, an average of $46 \%$ was used exclusively for dairy cattle and the remaining $54 \%$ was used both for cattle and agriculture. Total bacterial counts were significantly higher $(p<0,05)$ in milk samples derived from mixed animal and crop farms. By contrast, somatic cell count (SCC) was significantly lower $(p<0,05)$ in farms which milk producers presented higher level of education. In addition, a significant difference was observed regarding dry cow treatment $(p<0,01)$ and the use of artificial insemination $(p<0,05)$. For those farms with machine milking, there were significant 
differences $(p<0,01)$ regarding the equipment maintenance according to the level of education of producers. In summary, the level of education of producers plays a fundamental role in the adoption of good management practices in order to produce milk with high quality.

Keywords: Milking. Level of education. Dairy farming.

\section{NIVEL DE EDUCACIÓN DE PRODUCTORES RURALES Y DE LAS CARACTERÍSTICAS DE LA PRODUCCIÓN DE LECHE}

\section{RESUMEN}

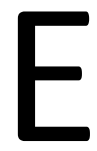

n Brasil, hay productores especializados de leche con alta producción y un número importante de pequeños productores que producen pequeño volumen de leche de baja calidad y el grado de educación puede determinar mejor las tasas de producción en el sector lechero. Este estudio tuvo como objetivo relacionar las diferentes formas de producción de leche para el nivel de educación de los productores. En 274 unidades de producción de leche (UPL) de Rio Grande do Sul se recogieron muestras de leche y fueron realizados encuestas epidemiológicas a los productores. En promedio, las UPL cuentan con 8,4 vacas lactantes y 4,4 vacas secas, produciendo 78,9 L/día, y la productividad de 9,3 L/vaca/día. Hay UPL que utilizan solo su área para la producción lechera (46\%) y otros que también la utilizan para la agricultura (54\%). El recuento total de bacterias (RTB) fue mayor en UPL con ambas actividades $(p<0,05)$, con un menor recuento de células somáticas (RCS) en el UPL que los productores son más escolarizados. Estos productores llevan a cabo con mayor frecuencia el tratamiento de vacas secas $(p<0,01)$ e realizan inseminación artificial $(p<0,05)$. Como para el ordeño, hay diferencia en la realización del mantenimiento de la maquina de ordeñe que se realiza más por los productores más instruidos $(p<0,01)$. La educación podría interferir en la adhesión de técnicas que se asocien con la calidad de la leche producida.

Palabras clave: Ordeño. Educación. Productor de leche.

\section{REFERÊNCIAS}

BEHMER, A. Como aproveitar bem o leite no sítio ou chácara. São Paulo: Nobel, 1984. 320p.

BRASIL. Instrução Normativa n. 62 de 29 de dezembro de 2011. Alteração do caput da Instrução Normativa MAPA no51, de 18 de setembro de 2002. Diário Oficial da União (da República Federativa do Brasil), Brasília, 29 dez. 2011. 
CBQL (Conselho Brasileiro de Qualidade do Leite). Comitê de equipamentos. Equipamentos de ordenha: recomendações do comitê de equipamentos. São Paulo, Quiron, 2004.

FOOD AND AGRICULTURE ORGANIZATION OF THE UNITED NATIONS - FAO. Milk and milk products, 2011. Disponível em <http://www.fao.org/docrep/011/ai474e/ai474e10.htm> Acesso em: 14 mai. 2013.

FREITAS, J. A.; OLIVEIRA, J. P.; SUMBO, F. D. Características físico-químicas e microbiológicas do leite fluido exposto ao consumo na cidade de Belém, Pará. Higiene Alimentar, v. 16, n. 10, p. 89-96, 2002.

GUO, M. R.; WANG, S.; LI, Z.; QU, J.; JIN, L.; KINDSTEDT, P. S. Ethanol stability of goat's milk. International Dairy Journal, v. 8, n. 1, p. 57-60, 1998.

Instituto Brasileiro de Geografia e Estatística - IBGE. Estatística da produção pecuária, 2013. Acessado em 19 fevereiro de 2014.

http://www.ibge.gov.br/home/estatistica/indicadores/agropecuaria/producaoagropecuaria/ abate-leite-couro-ovos_201303_publ_completa.pdf

KRUG, E. E. B.; REDIN, R. O.; KODAMA, H. K. SCHLICHTING, H. A.; ZACHIA, F. A. Manual da Produção Leiteira. Porto Alegre: CCGL, 1993. 716p.

MACHADO, P. F.; BARANCELLI, G.; PEREIRA, A. R. CCS: Leite com mais qualidade e melhor rendimento industrial. Indústria de Laticínios, v. 2, p. 65-68, 1998.

MILINSKI, C.; GUEDINE, P.; VENTURA, C. O Sistema agroindustrial do leite no Brasil: uma análise sistêmica. In: CONGRESSO BRASILEIRO DE SISTEMAS, 4., 2008, Franca. Anais. Franca: Centro Universitário de Franca - Uni-FACEF, 2008.

REBHUN, W. L. Doenças do Gado Leiteiro. São Paulo: Roca, 2000, p 339-370.

SCALCO, A. R.; SOUZA, R. C. Qualidade na cadeia de produção de leite: diagnóstico e proposição de melhorias. Organizações Rurais \& Agroindustriais, Lavras, v. 8, n. 3, p. 368377, 2006.

SCHNEIDER, S. A pluriatividade na agricultura familiar. Porto Alegre: UFRGS Editora, 2003. $254 p$. 